We gratefully acknowledge grants from the Nuffield Provincial Hospitals Trust and from the British Diabetic Association. One of us (M. G. F.) was a Research Fellow of the United Birmingham Hospitals Endowment Fund. We also acknowledge the skilled assistance given, often out of duty hours, by the staff of the biochemistry department of the General Hospital, Birmingham, by Mrs. M. Jones, secretary of that department, and by Sister E. S. Streather and Mrs. J. Calcutt, of the Diabetic Clinic. We acknowledge the help provided by the health visitors from the Public Health Department of the City of Birmingham, and to the students from the Medical School, Birmingham; also the helpful criticism of Professor K. Lundbaek and Dr. D. A. Pvke. Mr. D. H. Vobes also gave valuable assistance to the working party, and we are indebted to Messrs. Brown and Polson Ltd. for pachs of glucose.
REFERENCES

Diabetes Survey Working Party (1959). J. Coll. gen. Practit., 2. 189

Hoffman, W. S. (1937). J. biol. Chem., 120, 51.

Kemsley, W. F. F. (1952). Ann. Eugen. (Lond.), 16, 316.

Kenny, A. J., and Chute, A. L. (1953). Diabeles, 2, 187

- and Best, C. H. (1951). Canad. med. Ass. J., 65, 233.

Lawrence, R. D. (1947). Med. Clin. N. Amer., 31, 289.

McLean, H. (1922). Modern Methods in the Diagnosis and Treatment of Glycosuria and Diabetes, $3 \mathrm{rd}$ ed. Constable, London.

Marble, A. (1959). In Joslin's Treatment of Diabetes Mellitus. 10 th ed., p. 720 . Lea and Febiger, Philadelphia.

Redhead, I. H. (1960). Brit. med. J., 1, 695.

Schliack, V., and Weuffen, W. (1960). Z. ges. inn. Med., 15, 787.

Unger, R. H. (1957). Ann. intern. Med., 47, 1138 .

Walker, J. B., and Kerridge. D. (1961). Diabetes in an Englisht Community. Leicester Univ. Press.

Wilkerson. H. L. C., and Krall, L. P. (1947). J. Amer. med. Ass.. 135. 209

\title{
PREVALENCE OF GLYCOSURIA AND DIABETES MELLITUS*
}

\section{A COMPREHENSIVE SURVEY IN AN URBAN COMMUNITY}

BY

\author{
JOHN HARKNESS, M.B., D.P.H., D.I.H. \\ D.Obst.R.C.O.G. \\ Medical Officer of Health, Halstead Urban and Rural Districts
}

In 1946 Wilkerson and Krall (1947) carried out the first community diabetes survey. They tested $70.6 \%$ of the population of 4,983 in Oxford, Massachusetts, and found 40 known cases of diabetes and 30 new cases. The total incidence was $1.4 \%$. In Newmarket, Ontario, Kenny et al. (1951) tested $81 \%$ of the population over 6 years of age and found the incidence of diabetes to be $1.2 \%$. They found 54 cases of diabetes, of which 21 were new cases. Since then mass screening surveys have been carried out in the United States and Canada, and in 109 surveys over $1 \mathrm{~m}$. people have been tested. The incidence of diabetes in these surveys has varied between 1 and $1.5 \%$ (Joslin et al., 1959).

In this country Redhead (1960) tested a sample of a general practice in Newcastle ; 1,991 people were tested and he found 19 cases of diabetes, of which 10 were first discovered in his survey. More recently, in Ibstock, Walker and Kerridge (1961) tested $81 \%$ of the population over 5 years of age and found 33 known diabetics and another 25 unknown mild cases. Their survey estimated that the total percentage of known diabetics in Ibstock is between 1.3 and $1.4 \%$.

The aim of the present survey was to ascertain the prevalence of diabetes in Halstead, Essex, and to discover any unknown cases. An attempt was also made to classify the cases of non-diabetic glycosuria.

\section{Investigation}

The survey was confined to the Urban District of Halstead. Halstead is a market and industrial town in north-west Essex and the 1951 census gave its population as exactly 6,000 . The aim of the survey was to test a specimen of urine of each of the resident population. The testing of blood samples was also considered, but the practical difficulties ruled this out.

The survey extended over one year. The field work was done by two people-a recently retired health visitor who had worked in the town for 10 years and myself. - No effort was made to prepare the population by any type of publicity, but after the first few weeks' work

\footnotetext{
* A grant towards the cost of the field work was made by the British Diabetic Association.
}

had been done it was well known that such a survey was in progress.

Specimen bottles were delivered to each house in the town, together with a duplicated letter signed by all the doctors there. Four general practitioners work in the town in two partnerships, and the majority of people are patients of one or other of these partnerships. The explanatory letter described the aims of the survey, appealed for the co-operation of each person, and included a form which was to be completed and returned next. day with the bottles. The form required the householder to fill in the name, age, and occupation of each person in the house. Instructions were given to fill the bottles one hour after the main meal of the day. Details of any known diabetics in the house were obtained. In some cases these known diabetics submitted specimens for testing, but the majority did not. It was found that some people had recently had a specimen of urine tested. These included life insurance and antenatal examinations and investigations in hospital or by the general practitioner. It was decided that if the examination had been carried out within the past three months a further test was unnecessary. In doubtful cases a further sample was obtained. The bottles were collected on the following day together with the form. The electoral register was used as a basis for the survey; this was carried out street by street, and it was occasionally found that the house did not appear on the register as it had been unoccupied when the register was compiled. In these cases the house was included in the survey.

In the case of infants from whom it was impossible to obtain a specimen of urine the mothers were asked to press the end of a "clinistix" between two folds of a wet nappy and note the colour change and return the clinistix with the other specimens. All the urine specimens which were collected were tested with clinistix. The clinistix was dipped in the specimen of urine, withdrawn, and placed on top of the specimen bottle. If the end turned blue glucose was present. The blue colour normally develops within one minute, and in this survey all the clinistix strips were left for two minutes to allow the colour change to develop. All the 
specimens which gave a positive reaction with clinistix were tested with "clinitest."

Those persons who gave a positive reaction to clinistix were offered a blood-sugar examination. The known diabetics were excluded from this offer. Details of the biochemical tests of all the known diabetics were available, so it was not thought necessary to repeat these investigations. In most cases a glucose-tolerance test was performed, but in a few cases the fasting blood sugar was estimated instead:

The glucose-tolerance test was a modification of the standard test as described by May and Marrack (1951). A full diet was consumed up to 11 p.m. the night before the test. The patient attended, fasting, at 9 a.m. After a fasting blood sample had been obtained $50 \mathrm{~g}$. of glucose in water was taken by mouth and blood and urine samples were taken after three-quarters of an hour and after two hours. Venous samples were taken. The reasons that this test was used rather than the standard test with samples at half, one, and one and a half, and two hours were twofold. Firstly, this method was the one in common use by the laboratories doing the tests ; and, secondly, the large numbers involved and the fact that many of the tests had to be done in the patients' homes would have made the standard test very time-consuming. The specimens were tested in the pathological laboratories at the Essex County Hospital, Colchester, and St. John's Hospital, Chelmsford. The blood-sugar was measured by a modification of the method of Folin and Wu as described by Varley (1958). This method was further modified by the dilution of the blood with an isotonic solution of sodium sulphate; this prevents the release of glutathione, which is the chief substance other than glucose causing reduction. The method gives a result which is near the figure for true glucose.

\section{Diagnostic Criteria}

Fasting Blood Sugar.-A fasting level greater than $120 \mathrm{mg} . / 100 \mathrm{ml}$. and glucose in the fasting specimen was regarded as diagnostic of diabetes.

Glucose-tolerance Test.-The interpretation of this test was similar to that used by Redhead (1960) and was based on the criteria suggested by Harrison (1957).

Normal Curve.-Fasting level $80-120 \mathrm{mg} / 100 \mathrm{ml}$. of blood, three-quarters of an hour level less than 180 mg., return below $100 \mathrm{mg}$. by two hours, and no glucose in any urine specimen.

Diabetic Curve.-Fasting level greater than $120 \mathrm{mg}$./ $100 \mathrm{ml}$. and glucose in one or more urine specimens: diabetes diagnosed. Three-quarters of an hour level greater than $190 \mathrm{mg}$. $/ 100 \mathrm{ml}$.; time taken for return to below $100 \mathrm{mg}$. greater than two hours even though fasting level normal and glucose in one or more specimens of urine: diabetes diagnosed.

Lag-storage Curve.-Fasting level normal, threequarters of an hour level greater than $180 \mathrm{mg} . / 100 \mathrm{ml}$., time taken for return to below $100 \mathrm{mg}$. less than two hours, and glucose present in one or more urine specimens.

Renal Glycosuria Curve.-Normal curve as described above but glucose present in one or more urine specimens.

'The exception in the above criteria to those advocated by Harrison (1957) is the substitution of the threequarters of an hour level for the peak level. Harrison says that the highest point or peak of the curve is normally within the first hour. In the standard glucosetolerance test it is sometimes the half-hour and sometimes the one-hour level which is found to be the highest point of the curve. For practical purposes the threequarters of an hour level should in most cases give a reading that is near the peak of the curve.

The criteria for all these curves as described by Harrison are for capillary blood, while I have used the same criteria for venous blood. The fasting levels of capillary and venous blood are approximately the same, but after glucose the venous blood sugar may be lower than the capillary level.

\section{Postal Survey}

A certain number of bottles were returned empty or the people refused to take the bottles on the first occasion. Details of these refusals were collected and a letter signed by their own doctor was sent to each of these persons. With the letter was a small envelope contairing a clinistix, and printed on the envelope was the following:

\section{TICK COLOUR CHANGE: NO CHANGE BLUE OTHER COLOUR}

A stamped addressed envelope was also included for the return of the clinistix and the form. The clinistix was examined when it was returned and the colour change marked on the envelope was noted. This method is similar to that described by the Diabetes Survey Working Party of the College of General Practitioners (1959).

If any colour change was noted on the envelope or the clinistix was blue when returned, visits were made to the people concerned and postprandial specimens of urine obtained. The specimens were then tested with clinistix and clinitest, and if positive with clinistix the persons concerned were offered a glucose-tolerance test.

\section{Results}

A total of 5,562 people $(2,655$ males and 2,907 females) had a specimen of urine tested for glucose. A further 104 had recently been tested and 137 responded to the postal survey and tested themselves and returned the clinistix. Details were obtained of 40 persons who were reputed to be known diabetics and are not included in the previous figures. The total number covered by the survey was thus 5,843 , which represents $97.4 \%$ of the population of 6,000 (1951 Census). However, details of the refusals were collected, and of the 426 who refused initially, only 137 replied to the postal survey, 289 refusing. If the latter are added to the number covered by the survey the resident population of Halstead is found to be 6,132 and the percentage covered in the survey is $95.3 \%$

The details of the age-groups tested are shown in Table I ; the known diabetics are excluded.

Glycosuria.-Of the 5,562 people covered by the house-to-house survey 148 were found to have glycosuria. Six of those in the postal survey returned clinistix, noting that they had turned blue. Only four of these were blue when examined. Subsequent onehour postprandial urine specimens of the remaining two people failed to show any evidence of glycosuria. This was similar to the findings of the Diabetic Survey Working Party (1959), half of whose results were noted as blue though no colour change was seen when the clinistix was examined by the practitioner. It assumed that these mildly positive tests were due to contamina- 
TABle 1.-Age Distribution of 5,803 People Tested in House-toHouse Survey, Recently Tested, or who Responded to Postal Survey (Known Diabetics Excluded)

\begin{tabular}{|c|c|c|c|c|c|c|c|c|}
\hline \multirow{2}{*}{$\begin{array}{c}\text { Age } \\
\text { in } \\
\text { Years }\end{array}$} & \multicolumn{2}{|c|}{$\begin{array}{c}\text { Tested During } \\
\text { House-to- } \\
\text { House Survey }\end{array}$} & \multicolumn{2}{|c|}{$\begin{array}{l}\text { Recently Tested } \\
\text { by Own Doctor, } \\
\text { Hospital, etc. }\end{array}$} & \multicolumn{2}{|c|}{ Postal Survey } & \multicolumn{2}{|c|}{ Total } \\
\hline & $\mathbf{M}$ & F & $\mathbf{M}$ & $\mathbf{F}$ & $\mathbf{M}$ & F & $\mathbf{M}$ & $\mathbf{F}$ \\
\hline $\begin{array}{c}0-9 \\
10-19 \\
20-29 \\
30-39 \\
40-49 \\
50-59 \\
60-69 \\
70-79 \\
80-89 \\
90-99\end{array}$ & $\begin{array}{r}377 \\
348 \\
311 \\
374 \\
385 \\
370 \\
281 \\
162 \\
44 \\
3\end{array}$ & $\begin{array}{r}423 \\
420 \\
284 \\
379 \\
362 \\
395 \\
348 \\
220 \\
70 \\
6\end{array}$ & $\begin{array}{l}1 \\
1 \\
7 \\
3 \\
5 \\
5 \\
4 \\
5 \\
1 \\
-\end{array}$ & $\begin{array}{r}2 \\
5 \\
15 \\
7 \\
10 \\
12 \\
15 \\
6 \\
-\end{array}$ & $\begin{array}{r}1 \\
4 \\
6 \\
8 \\
5 \\
12 \\
17 \\
5 \\
=\end{array}$ & $\begin{array}{c}6 \\
3 \\
6 \\
7 \\
13 \\
21 \\
17 \\
6 \\
-\end{array}$ & $\begin{array}{r}379 \\
353 \\
324 \\
385 \\
395 \\
387 \\
302 \\
172 \\
45 \\
3\end{array}$ & $\begin{array}{r}425 \\
431 \\
302 \\
392 \\
379 \\
420 \\
384 \\
243 \\
76 \\
6\end{array}$ \\
\hline Total & 2,655 & 2,907 & 32 & 72 & 58 & 79 & 2,745 & 3,058 \\
\hline
\end{tabular}

tion of the clinistix by the patient's fingers when testing. There were thus 152 cases of glycosuria, and details were available of 40 reputed cases of diabetes with evidence of glycosuria on previous occasions. Therefore there were 192 cases of glycosuria among 5,843 people covered by the survey-an incidence of $3.3 \%$. Of 150 specimens tested with clinitest, $64(42.1 \%)$ were positive and 86 negative. The 40 "known" diabetics and two of those with a positive clinistix in the postal survey did not have specimens tested with clinitest. Of the 192 cases of glycosuria, 121 were in males and 71 in females-63\% and $37 \%$ respectively; only five were under the age of 20 years. The age distribution is shown in Table II.

TABLE II.-Age Distribution of Persons with Glycosuria

\begin{tabular}{c|c|c|c}
\hline Age in Years & Male & Female & Total \\
\hline $0-9$ & 1 & -4 & 1 \\
$10-19$ & $\frac{4}{20}$ & 6 & 26 \\
$20-29$ & 14 & 3 & 17 \\
$30-39$ & 26 & 5 & 31 \\
$40-49$ & 17 & 29 & 30 \\
$60-59$ & 20 & 8 & 49 \\
$70-79$ & 16 & 3 & 10 \\
$80-89$ & 7 & 71 & 192 \\
\hline Total & 121 & 79 \\
\hline
\end{tabular}

Blood-sugar Examinations.-Glucose-tolerance tests were performed in 109 cases and fasting blood sugar was estimated in 13. Details were also available of three cases in which glucose-tolerance tests had been done previously. In 27 cases of glycosuria blood examinations were not done. The details of these are described later.

Diabetes. - Previously undiagnosed diabetes was discovered in 35 people $(0.57 \%)$ and details were available of 38 known cases $(0.62 \%)$ (34 males and 39 females). This gives a rate of $1.2 \%$ of the population. Of the cases of glycosuria, $38 \%$ were diabetics. Table III shows the age distribution of the cases.

Previously Known Cases.-Details were obtained of 40 people who said they were known diabetics. All their records were available and 38 satisfied the diagnostic

TaBLE III.-Distribution of Known and New Cases of Diabetes

\begin{tabular}{|c|c|c|c|c|c|c|}
\hline \multirow{2}{*}{$\begin{array}{c}\text { Age } \\
\text { in } \\
\text { Years }\end{array}$} & \multicolumn{2}{|c|}{ Known Cases } & \multicolumn{2}{|c|}{ New Cases } & \multicolumn{2}{|c|}{ Total Cases } \\
\hline & Male & Female & Male & Female & Male & Female \\
\hline $0-9$ & - & -1 & - & - & - & - \\
\hline $\begin{array}{r}10-19 \\
20-29\end{array}$ & $\overline{2}$ & 1 & 二 & 二 & $\overline{2}$ & 1 \\
\hline $\begin{array}{l}30-39 \\
40-49\end{array}$ & $\frac{7}{6}$ & 1 & $-\frac{3}{3}$ & $=$ & $\frac{-1}{9}$ & 1 \\
\hline $50-59$ & 2 & $\overline{3}$ & 2 & $\overline{5}$ & $\begin{array}{l}9 \\
4\end{array}$ & 8 \\
\hline $\begin{array}{l}60-69 \\
70-79\end{array}$ & $\frac{2}{2}$ & $\begin{array}{r}14 \\
2\end{array}$ & $\begin{array}{l}7 \\
4\end{array}$ & $\begin{array}{r}8 \\
3\end{array}$ & $\begin{array}{l}9 \\
6\end{array}$ & $\begin{array}{r}22 \\
5\end{array}$ \\
\hline $80-89$ & 1 & 2 & 3 & - & 4 & 2 \\
\hline
\end{tabular}

D criteria laid down. Of the two others, one was a case of renal glycosuria and the other had had a single blood-sugar estimation which was normal, so no firm diagnosis could be made. The age of these 38 known diabetics varied from 11 to 84 years, with a preponderance of cases in the 60-69 age-group. Of the 16 patients in this age-group 14 were women. There was no marked difference in the other age-groups.

New Cases.-Thirty-five previously unknown cases were discovered by this survey. There was no great difference in incidence between the sexes, 16 cases occurring in females and 19 in males. All the new cases were in persons above the age of 40 years, and the maximum incidence, 15 cases, was in the age-group 60-69 years. Thirty-three gave a positive reaction to clinitest and only two were negative.

Renal Glycosuria.-Of the 37 cases of renal glycosuria diagnosed, 28 were in males and 9 in females: 33 were diagnosed by glucose-tolerance tests done during the survey, three were known cases whose records were available, and one subject was reputed to be a diabetic, but her records showed her to be suffering from renal glycosuria. There were 26 cases negative to clinitest and 10 positive. One case did not have a specimen tested. The incidence of renal glycosuria was $19.3 \%$ of the cases of glycosuria and $0.63 \%$ of those tested. There were two expectant mothers. in this group. One man aged 67 had had a glucose-tolerance test performed 25 years previously and the present test showed no change in the condition.

Lag-storage Glycosuria.-There were only six cases of this condition-five in males and one in a female. All gave a positive reaction to clinistix and three to clinitest. All had a fasting level below $103 \mathrm{mg} . / 100 \mathrm{ml}$., a three-quarters of an hour level of between 200 and $231 \mathrm{mg} . / 100 \mathrm{ml}$., and all were well below $100 \mathrm{mg} . /$ $100 \mathrm{ml}$. after two hours.

Unclassified Cases with Hyperglycaemia.-There were four patients whose glucose-tolerance curves did not satisfy the criteria of any of the conditions so far described. The details of their glucose-tolerance curves are shown in Table IV. During the glucose-tolerance

TABLE IV.-Details of Blood Sugars (in mg./100 ml.) of Four Patients with Hyperglycaemia without Glycosuria

\begin{tabular}{|c|c|c|c|c|}
\hline Sex & Age & Fasting Level & \&'hour Level & 2-hour Leve \\
\hline $\begin{array}{l}\text { Male } \\
\text { Female } . . \\
\text { Male } \quad \ldots \\
,,\end{array}$ & $\begin{array}{l}68 \\
67 \\
63 \\
54\end{array}$ & $\begin{array}{l}113 \\
110 \\
122 \\
123\end{array}$ & $\begin{array}{l}221 \\
205 \\
217 \\
152\end{array}$ & $\begin{array}{l}144 \\
140 \\
103 \\
129\end{array}$ \\
\hline
\end{tabular}

test none of the specimens of urine showed any evidence of glycosuria. One was positive to clinitest and three were negative in the initial screening. If they had shown glycosuria during the glucose-tolerance test they would all have satisfied one or other of the criteria necessary to establish a diagnosis of diabetes. Three of these cases have a high threshold. Griffiths (1960) says that in long-standing diabetes the threshold may rise and there may be no glucose in the urine at blood levels over $200 \mathrm{mg} . / 100 \mathrm{ml}$. Further, he states that glycosuria is therefore not essential for the diagnosis of diabetes. Joslin et al. (1959), however, consider glycosuria essential for a diagnosis of diabetes. Most investigators would regard these cases as mild diabetes, which require careful observation and further tests at frequent intervals.

Normal Curves. - Thirty-four cases of glycosuria were found to have normal curves after a glucose-tolerance 
test. All the cases were positive to clinistix and six were positive to clinitest.

No Diagnosis. - Ten people had normal fasting bloodsugar levels, and as they did not have a glucose-tolerance test no diagnosis could be made. One subject who was reputed to be a "known" diabetic had had only a single blood-sugar test done; as this was within normal limits no diagnosis could be made.

No Blood Tests.-There were 27 persons who had no blood tests done. Two died from cerebral vascular accidents before the tests could be carried out. Four moved out of the district and failed to respond to letters. Two had subsequent postprandial tests which were negative: one was a 14-year-old mentally retarded girl who resisted an attempt to perform a blood-sugar test, and the other was an expectant mother in the last month of her pregnancy whose urine showed no evidence of glycosuria after delivery. Of 19 persons who refused to undergo a blood examination, 14 were negative and 5 positive to clinitest.

The details of the blood tests done and classification of all cases of glycosuria are shown in Table $\mathrm{V}$.

Table V.-Details of Blood Tests Done and Classification of all Cases of Glycosuria

\begin{tabular}{|c|c|c|c|c|c|c|}
\hline \multirow[b]{2}{*}{ Diagnosis } & \multicolumn{2}{|c|}{$\begin{array}{c}\text { Blood Tests Done } \\
\text { During Survey }\end{array}$} & \multicolumn{2}{|c|}{$\begin{array}{c}\text { Blood Tests Done } \\
\text { Previously }\end{array}$} & \multirow{2}{*}{$\begin{array}{c}\text { No } \\
\text { Blood } \\
\text { Tests } \\
\text { Done }\end{array}$} & \multirow[b]{2}{*}{ Total } \\
\hline & $\begin{array}{c}\text { Glucose- } \\
\text { tolerance } \\
\text { Tests }\end{array}$ & $\begin{array}{l}\text { Fasting } \\
\text { Blood } \\
\text { Sugar }\end{array}$ & $\begin{array}{c}\text { Reputed } \\
\text { to be } \\
\text { "Known" } \\
\text { Diabetics }\end{array}$ & $\begin{array}{l}\text { Other } \\
\text { Blood- } \\
\text { sugar } \\
\text { Tests }\end{array}$ & & \\
\hline $\begin{array}{l}\text { Diabetes: } \\
\text { Confirmed } \\
\text { known cases } \\
\text { New cases } \\
\text { Renal glycosuria } \\
\text { Lag storage } \\
\text { Unclassified } \\
\text { hyperglycaemia } \\
\text { Normal blood } \\
\text { sugar .. } \\
\text { None-insufficient } \\
\text { tests } \ldots \\
\text { No blood tests }\end{array}$ & $\begin{array}{r}32 \\
33 \\
6 \\
4 \\
34\end{array}$ & 10 & $\begin{array}{r}38 \\
1\end{array}$ & 3 & 27 & $\begin{array}{r}38 \\
35 \\
37 \\
6 \\
\\
4 \\
34 \\
11 \\
27\end{array}$ \\
\hline Total .. & 109 & 13 & 40 & 3 & 27 & 192 \\
\hline
\end{tabular}

\section{Discussion}

The proportion of the population tested (95\%) is higher than that of any of the other surveys. This was due to the method of collection of the specimens. The distribution and collection of bottles was extremely laborious and several visits had to be made to a large number of households before all the bottles were collected.

The response to the postal survey was disappointing -only $137(32.1 \%)$ out of 426 persons replying. However, it should be remembered that all these refused in the first instance. This response is similar to that found in the survey by Fuenning et al. (1960), who circularized 1,600 university employees and only 584 $(36.5 \%)$ replied. They felt that most people would test a specimen with the clinistix which was enclosed, but if it was negative would not trouble to reply. I think that most people in Halstead, having heard so much about this survey from neighbours, would show sufficient curiosity to test their urine with the clinistix which was sent to them and only a minority would take no action. However, it is possible that a patient testing his own urine might have failed to report a positive because of apprehension or fear.

Clinistix was found to be excellent for the rapid testing of large numbers of specimens. It indicated the people who required more detailed tests and obviated the necessity for blood tests on the whole population. Eighty-seven cases that were positive to clinistix were negative when tested with clinitest, but 34 of these had an abnormal blood-sugar curve. Only two of the cases of diabetes gave a negative reaction to clinitest, and subsequent inquiries and further tests showed that these two subjects had submitted early morning specimens. Their one-hour postprandial specimens gave a positive result with clinitest.

Almost half the diabetics in the town were discovered as a result of the survey. The incidence $(1.2 \%)$ is very similar to that in other surveys. Walker $(1959 a, 1959 b)$ found the incidence of diabetes to be $1.39 \%$. Redhead (1960), in Newcastle, found it to be $0.95 \%$. Kenny et al. (1951), in Canada, found it to be $1.2 \%$, and with Wilkerson and Krall (1947) it was $1.4 \%$. The newly discovered cases were also approximately in the numbers to be expected from other surveys. Comparison between surveys is difficult as the results vary according to the age-and-sex distribution of the population tested. Different methods of urine sampling and testing and of blood-sugar measurement, and different diagnostic criteria, introduce further difficulties in comparing results.

There was a remarkably low incidence of lag-storage glycosuria in the present survey, and this may have been due to one of two reasons. The use of venous blood gives a peak level which is lower than the peak level when capillary blood is used. The use of the threequarters of an hour level may also have failed in some cases to give as high a peak level as would have been given with the half- and one-hour levels.

The real problem of all cases of non-diabetic glycosuria is the follow-up to ensure that they do not progress to frank diabetes and to diagnose them before the disease becomes established.

\section{Conclusion}

This survey has confirmed other studies and shown that there are a large number of undiagnosed diabetics in the community. If the incidence of 6 per 1,000 is applied to the country as a whole, it will be seen that there may be as many as 300,000 undiagnosed cases.

This survey has described a method of detecting diabetes, but such a method is unlikely to be practicable for most health departments. It has been suggested (B.M.J., 1959) that the detection of cases of latent diabetes is a challenge to the family doctor. However, many people never attend their doctor, and this makes the challenge more formidable.

The institution of diabetic detection drives is a fresh avenue for the preventive medical services to explore. With the development of the clinistix method of testing, the community detection drive becomes a practical reality. This survey has shown that a postal detection drive could be instituted. Under the age of 20 years only mild cases of glycosuria of no significance were discovered. A mass postal survey, area by area, should be confined to those over the age of 21 years. The electoral register should be taken as a target. Each two or perhaps three years a clinistix would be posted to each person on the register giving instructions how to use it. The instructions would include directions for each positive reactor to take a one-hour postprandial specimen of urine to his own doctor or to a clinic set up for the purpose. This specimen should be tested 
with clinitest and if it is positive a glucose-tolerance test should be done. The people whose urine was negative to clinitest would be instructed to bring onehour postprandial specimens on two subsequent occasions. If either of these were positive a bloodsugar examination would be done, but if they were all negative the patient would be instructed to report back in six months. I suggest that such a scheme is possible and very worth while.

\section{Summary}

The results of a comprehensive survey in Halstead, Essex, are reported. Out of 5,843 persons $(95.3 \%$ of the population) included in the survey, 192 cases of glycosuria were discovered-38 known cases of diabetes and 35 newly discovered cases-a total incidence of $1.2 \%$. The newly discovered cases were in subjects over 40 years, and the maximum incidence was in the 60-69 age-group.

An attempt was made to classify the other cases of glycosuria into various types. If accurate comparisons are to be made it is essential that comparable methods of blood-sugar analysis and comparable diagnostic criteria are used.

The survey confirmed the findings of other surveys that for every known diabetic there is another undiagnosed case. There may be as many as 300,000 undiagnosed cases in the country, and some suggestions are made for the institution of a large-scale postal diabetes detection drive.

It would have been impossible to do this work without the help of a great number of people. Dr. K. J. Atkinson, Dr. W. A. L. Collier, Dr. A. H. Rea, and Dr. P. Train are the four general practitioners in Halstead without whose help the survey would have been impossible. I received great help and encouragement from Dr. S. A. Propert, consultant physician, and Dr. J. B. Penfold, consultant pathologist to the Colchester Hospital Group. The biochemical work was done by Mr. Day, biochemist, Essex County Hospital, Colchester, and Mr. Broughton, biochemist, St. John's Hospital, Chelmsford. I am particularly indebted to $\mathrm{Mr}$. Day for much advice and encouragement. Miss M. H. Bowman, S.R.N., was responsible for half of the field work, and her enthusiasm ensured the completion of the survey. I gratefully acknowledge the assistance I have received from Dr. I. H. Redhead's work, which initiated my interest in such a survey. I am grateful to Ames and Co. for supplying the clinistix and clinitest, and to Mr. Wakeling of that firm for his interest and encouragement.

\section{REFERENCES}

Brit. med. J., 1959, 2, 555.

Diabetes Survey Working Party (1959). J. Coll. gen. Practit., $2,189$.

Fuenning, S. I., Rose, K. D., Nebe, F. M., and Knipmeyer, C. (1960), Neb. St. med. J., 45, 70.

Griffiths, W. J. (1960). Practitioner, 184, 390

Harrison, G. A. (1957). Chemical Methods in Clinical Medicine, 4th ed. Churchill, London.

Joslin, E. P., Root, H. F., White, P., and Marble, A. (1959). The Treatment of Diabetes Mellitus, 10th ed. H. Kimpton, London.

Kenny, A. J., Chute, A. L., and Best, C. H. (1951). Canad. med. Ass. J., 65, 233 .

May, H. B., and Marrack, J. R. (1951). In Panton and Marrack's Clinical Pathology, 6th ed. Churchill, London.

Redhead, 1. H. (1960). Brit. med. J., 1, 695.

Varley, H. K. (1958). Practical Clinical Biochemistry, 2nd ed. Heinemann, London.

Walker, J. B. (1959a). J. Endocr., 18, xviii.

- (1959b). Postgrad. med. J., 35, 302. and Kerridge, D. (1961). "Diabetes in an English Com munity. Leicester Univ. Press.

Wilkerson. H. L. C., and Krall, L. P. (1947). J. Amer. med. Ass. 135, 209.
INTRAVENOUS GLUCOSE TOLERANCE AS A TOOL IN DEFINITION AND DIAGNOSIS OF DIABETES MELLITUS*

BY

KNUD LUNDBAEK, M.D.

Professor of Medicine, Arhus University School of Medicine, Arhus, Denmark

Since 1917 the glucose-tolerance test has been the procedure on which the definition of diabetes mellitus is based and the means by which the diagnosis of diabetes mellitus is made when other evidence is doubtful.

The test introduced by Jacobsen (1917) was the oral one. Jørgensen and Plum (1923) tried to establish an intravenous glucose-tolerance test, but did not succeed. During the past 20 years some workers have occupied themselves with intravenous glucose tolerance; a few have advocated its use, but most have devoted themselves to the mathematical problems involved in the analysis of the blood-sugar variations after the intravenous injection of glucose. In the meantime the oral glucose-tolerance test has held the field as the timehonoured means of the definition and diagnosis of diabetes mellitus.

In this article I want to suggest that the time has come when we ought seriously to consider discarding the oral glucose-tolerance test and adopting the intravenous one for the definition as well as for the diagnosis of diabetes mellitus.

However, strictly speaking, glucose tolerance cannot be used to define diabetes mellitus but can only be a means of defining the diabetic state or the degree of " diabeticity."

If we want to use glucose tolerance as the definitory tool for diabetes mellitus we must include it in a definition, which could be like this:

\section{Diabetes Mellitus and Diabetic Aberration}

Diabetes Mellitus: A chronic disease with reduced glucose tolerance in patients not suffering from disease of the pancreas or from acromegaly, Cushing's disease, or phaeochromocytoma.

Diabetic aberration: Any other condition with transitory or permanent reduction of glucose tolerance.

The "other conditions" would be the endocrine disease mentioned and conditions such as fever, starvation, emotional upset, liver disease, brain disease, etc.

This definition stresses the difference between, on the one hand, a very common disease of unknown nature and, on the other hand, a series of unusual diseases in which the diabetic state is an understandable part of the clinical picture and a few more or less well defined, usually transitory, physiological and pathological states.

I do not intend to discuss the problems of definition of diabetes mellitus in more detail, but before leaving it it should be said that so long as the exact mechanism of a disease is not known any definition is, of course, in a certain sense arbitrary, and depends upon the use to which it is to be put. If it be suggested to-day that

* Based on a communication to a meeting of the British Diabetes Association in Birmingham, September, 1961. 